\title{
Dietary Phytochemical Screening of Spider Plant (Gynandropsis gynandra (L.) Briq.) Accessions From Africa and Asia to Identify Genotypes for Use in Nutraceutical Breeding
}

\section{OPEN ACCESS}

Edited by:

Giuseppina Rea,

National Research Council (CNR), Italy

Reviewed by:

Umakanta Sarker

Bangabandhu Sheikh Mujibur Rahman

Agricultural University, Bangladesh

Shyamal Nandi,

Govind Ballabh Pant National Institute

of Himalayan Environment and

Sustainable Development, India

${ }^{*}$ Correspondence:

Barthlomew Yonas Chataika barthchataika@gmail.com

Specialty section:

This article was submitted to Crop Biology and Sustainability, a section of the journal

Frontiers in Sustainable Food Systems

Received: 30 June 2021 Accepted: 03 September 2021 Published: 05 October 2021

Citation:

Chataika BY, Akundabweni LS-M, Houdegbe AC, Achigan-Dako EG,

Sibiya J and Masamba K (2021) Dietary Phytochemical Screening of Spider Plant (Gynandropsis gynandra (L.) Briq.) Accessions From Africa and Asia to Identify Genotypes for Use in

Nutraceutical Breeding.

Front. Sustain. Food Syst. 5:733909.

doi: 10.3389/fsufs.2021.733909
Barthlomew Yonas Chataika ${ }^{1 *}$, Levi Shadeya-Mudogo Akundabweni ${ }^{1}$, Aristide Carlos Houdegbe ${ }^{2,3}$, Enoch G. Achigan-Dako ${ }^{2}$, Julia Sibiya ${ }^{3}$ and Kingsley Masamba ${ }^{4}$

${ }^{1}$ Crop Science Department, Faculty of Agriculture and Natural Resources, University of Namibia, Oshakati, Namibia, ${ }^{2}$ Laboratory of Genetics, Biotechnology, and Seed Science, Faculty of Agronomic Sciences, University of Abomey-Calavi, Cotonou, Benin, ${ }^{3}$ School of Agricultural, Earth and Environmental Sciences, University of KwaZulu-Natal, Pietermaritzburg, South Africa, ${ }^{4}$ Department of Food Science and Technology, Lilongwe University of Agriculture and Natural Resources, Lilongwe, Malawi

Increased public awareness of healthy foods and healthy living, coupled with escalating medicinal costs and recent advances in research and technology, has sparked a paradigm shift to nutraceuticals, which guarantee human health and disease prevention. Spider plant (Gynandropsis gynandra) contains dietary phytochemicals with high nutritional and medicinal properties that can contribute to healthy living. A study was conducted to identify spider plant (Gynandropsis gynandra (L.) Briq.) accessions with superior levels of dietary phytochemicals and anti-oxidative activity for use in nutraceutical breeding. Thirty-three accessions of spider plant, representing a wide genetic diversity based on geographic areas of origin (Asia, East Africa, Southern Africa, and West Africa), were used. Total phenolic acids, tannins, and anthocyanins were extracted and quantified using the Folin-Ciocalteau colorimetric, spectrophotometric, and $\mathrm{pH}$ differential methods, respectively. Antioxidant activity was determined using phosphomolybdenum method. Results showed significant variation in levels of total phenolic compounds, tannins, anthocyanins, and antioxidant activity $(P<0.05)$ amongst the spider plant accessions and regions of origin; ODS-15-037 (464 mg TAE/g DW), ODS-15-053 (270 mg GAE/g DW), and BC-02A (127 mg cyanidin-3-glucoside/g DW) had the highest levels of total tannins, phenolic compounds, and anthocyanins, respectively. Antioxidant activity was high in ODS-15053 (492.2 mg AAE/100 g DW), NAM 2232 (445.3 mg AAE/100 g DW), and NAM6 (432.5 mg AAE/100 g DW). On average, West African accessions had significantly high tannin concentrations (239 mg TAE/g DW), while Southern Africa accessions contained significantly high anthocyanin content (58.9 mg cyanidin-3-glucoside/g DW). The superior accessions are potential candidates for use in nutraceutical breeding, while the regions of origin could be used as gene pools for specific phytochemicals for improving dietary supplements of nutraceuticals. The strong antioxidant activity exhibited by spider plant accessions suggests the presence of compounds responsible 
for scavenging free oxygen or nitrogen radicals. Further studies are recommended to identify the chromosomal regions that contain genes controlling the dietary nutraceuticals in the genetic materials and to determine their association with foliage yield and other phenotypes, which can be utilized in spider plant improvement.

Keywords: dietary phytochemicals, nutraceutical breeding, indirect selection, free radicals, accessions, spider plant, antioxidant

\section{INTRODUCTION}

Global economic development continues to influence the changes in disposable incomes, spending levels, and quality of lifestyle associated with major diseases related to nutritional deficiencies (Pandey et al., 2010). Increased public awareness regarding healthy eating and living, escalating medical costs, and recent advances in research and technology have ignited a paradigm shift to nutraceuticals (Das et al., 2012), promising good health and disease prevention.

The nutraceuticals, such as vitamins, minerals, and phenolics, reduce the risk of chronic diseases by scavenging reactive oxygen and nitrogen species in the human body (Zhang et al., 2015; Sarker and Oba, 2018d) and are thus referred to as antioxidants (Sarker et al., 2018b). Over a couple of decades, there has been an interest in utilizing natural antioxidants from leaves of plant species, particularly for different types of pigments (Sarker and Oba, 2019a), phenolic acids (Sarker et al., 2018a), flavonoids (Sarker and Oba, 2018a), and vitamins C, $\mathrm{E}$, and A (Sarker and Oba, 2020e). The leaves are also the essential sources of minerals, such as microelements (Sarker et al., 2017) and macroelements (Chakrabarty et al., 2018), protein (Sarker and Oba, 2019d), dietary fiber (Keleş et al., 2016), vitamins (Sarker et al., 2015a) and carbohydrates (Sarker et al., 2015b) for human food supplements. The indigenous vegetables, commonly consumed by the local population, are reported to contain higher levels of dietary phytochemicals and antioxidant activity than commercial and exotic vegetables (Moyo et al., 2013; Chepkwony et al., 2020), suggesting their importance and inclusion in healthy diets. Among different orphan crops, the spider plant (Gynandropsis gynandra (L.) Briq.; family-Cleomaceae), a semi-wild indigenous vegetable species in sub-Saharan Africa (Shilla et al., 2019), has gained recent attention due to the presence of high levels of secondary metabolites which contribute to strong antioxidant properties (Sowinmi and Afolayan, 2015), and therefore, chosen for this investigation.

Studies on nutritional value and medicinal use of $G$. gynandra have suggested the high potential of the vegetable in the nutraceutical industry (van der Walt et al., 2009). The important nutraceutical phytochemicals in spider plant include phenolic compounds (Adhikari and Paul, 2018), tannins (Kutsututsa et al., 2014), and anthocyanins. These phytochemicals are reported to have antioxidant and therapeutic characteristics, including anti-inflammatory (Narendhirakannan et al., 2005), anticancerous (Bala et al., 2010), anti-diabetic (Trilochana et al., 2017), immunomodulator, and free radical scavenging (Adhikari and Paul, 2018) properties and other agerelated disorders (Anbazhagi et al., 2009).

Although the above studies report the medicinal and nutraceutical role of G. gynandra, the levels of the important phytochemicals in spider plant accessions have not been conclusively investigated. For example, Chweya and Mnzava (1997) observed that phytochemical research in G. gynandra mainly focused on individual compounds, with very little done on quantification and assessment of genetic variability. From the available literature, it is evident that studies have concentrated on quantifying the nutritional levels while ignoring the nutraceutical potential. Some phytochemicals are believed to be associated with the species' phenotype that can allow selection if the relationships are adequately investigated. For example, the purple color is believed to be linked to bitter taste due to high anthocyanin content, which also affects the nutraceutical potential of the plant and influences the willingness of consumers to utilize the plant as food (Mueller-Harvey, 2001) or medicine (Sogbohossou et al., 2020).

Tannins produce pronounced astringent properties associated with binding and gelatin precipitation from solution, consequently affecting the nutritive value of foods and feedstuffs eaten by humans and animals, respectively (Mueller-Harvey, 2001). In addition, researchers in Zimbabwe (Kutsututsa et al., 2014) observed the need for variability in tannin levels to employ crop improvement techniques to reduce the bitterness in G. gynandra genotypes without compromising the nutraceutical properties. Their observation pointed toward the need for adequate genetic characterization of spider plant accessions to quantify tannin levels. Although they screened and identified a superior genotype, their research was only limited to five genotypes. Thus, determining genetic diversity from a wider gene pool remains key to identifying superior candidates for use in demand-driven crop improvement programs.

Phenolic compounds and tannins are amongst the most important phytochemicals responsible for antioxidant and therapeutic properties in spider plant. The antioxidant activity of phenolic compounds is attributed to their ability to break the strong chains and scavenge the free radicals to provide protection against reactive oxygen species (Uusiku et al., 2010). These compounds account for the spider plant's potential to treat a number of non-communicable diseases, including hypertension, diabetes, cancer, and other cardiovascular diseases (Kumari and Jain, 2012; Kutsututsa et al., 2014). In addition, tannins are reported to enhance glucose uptake, insulin functions and regeneration of beta cells (Anderson and Polansky, 2002), 
protection of kidneys, and the relief of sore throats and diarrhea (Tuli et al., 2016).

The null hypothesis was that no difference exists in the dietary phytochemical content (total phenolic compounds, anthocyanins, and tannins) and in antioxidant activity amongst 33 accessions of spider plant (G. gynandra), representing a wide genetic diversity based on geographic areas of origin (Asia, East Africa, Southern Africa, and West Africa). The study's objectives were to screen and identify spider plant accessions, with high levels of dietary phytochemicals and antioxidant activity, for use in nutraceutical breeding.

\section{MATERIALS AND METHODS}

\section{Analytical Chemicals}

The analytical chemicals used in the study were Folin-Ciocalteu phenol reagent, gallic acid (3,4,5-trihydroxy benzoic acid), sodium hydrogen carbonate $\left(\mathrm{NaHCO}_{3}\right)$, methanolic solution, Folin-Denis solution, $\mathrm{Na}_{2} \mathrm{CO}_{3}$, gallic acid solution, sulphuric acid, sodium phosphate, ammonium molybdate, ascorbic acid, hydrochloric acid, potassium chloride, and Natrium/sodium acetate. All the chemicals used were of analytical grade and were obtained from SAAR Chem-Trade Pvt. Ltd, Mumbai, India.

\section{Trial Establishment and Collection of Phenotypic Data}

The trial was established in Lilongwe, Malawi $\left(1138 \mathrm{~m}\right.$ asl; $13^{\circ}$ $50^{\prime} 58^{\prime \prime} \mathrm{S} \& 33^{\circ} 46^{\prime} 07^{\prime \prime} \mathrm{E}$ ) in June 2020 under irrigation. The area comprises of fertile dark loam soils belonging to the class of luvisols. It is characterized by a medium amount of rainfall of around $900 \mathrm{~mm}$ per annum, and temperatures range from 17 to $27^{\circ} \mathrm{C}$. The 33 accessions of spider plant (Table 1), which originated from Asia, East Africa, Southern Africa, and West Africa, were grown in an $11 \times 3$ alpha lattice design, replicated three times. Accessions were planted in single rows of three meters long, $0.3 \mathrm{~m}$ inter-row spacing. Seeds were soaked in warm water $\left(40^{\circ} \mathrm{C}\right)$ for $30 \mathrm{~min}$ before planting to enhance germination. The field was kept weed-free by manual weeding and moist through regular watering. Watering was done every day during the first 14 days and then reduced to once every three days. Basal NPK fertilizer $(23: 21: 0+4 \mathrm{~S})$ was applied at planting at the rate of $40 \mathrm{~kg} \mathrm{~N} \mathrm{ha}^{-1}$.

Phenotypic data, including quantitative and qualitative traits, were collected when the accessions reached 50\% flowering, which was six weeks after planting. The quantitative phenotypic data was the number of leaves per plant. Qualitative data collected included stem trichome density, stem color, petiole trichome density, petiole color, growth tip trichome density, leaf color, leaf trichome density, and flower color. All the qualitative data were collected as described by Sogbohossou et al. $(2018,2019)$.

\section{Sample Preparation and Extraction}

Mature leaf samples were harvested six weeks after planting when the plants were at the $50 \%$ flowering stage. Leaf samples were cleaned with distilled water and freeze-dried using liquid nitrogen before being transported to the Lilongwe University of Agriculture and Natural Resources (LUANAR) nutrition laboratory for analysis of dietary phytochemicals. The phytochemical extraction from the leaf samples was done following the method described by Chaves et al. (2020) with minor modifications. Freeze-dried leaf samples were ground in a mechanical grinder to obtain a homogenous powder. The phytochemicals were extracted using $80 \%$ methanol in a 1:4 w/v ratio for $24 \mathrm{~h}$ with continuous shaking. The extracts were filtered using a Whatman no. 1 filter paper (Whatman International Ltd., Maidstone, England), and the filtrate/extracts were concentrated by evaporating excess solvent using a Buchi Rotavapor-R-205, at $40^{\circ} \mathrm{C}$. The extracts were diluted in a $1: 4 \mathrm{w} / \mathrm{v}$ ratio in $80 \%$ methanolic solution to obtain absorbance readings that were within the standard curve concentration range of $0.0-200.0 \mathrm{mg}$ gallic acid equivalent (GAE)/mL for total phenolic content determination.

\section{Determination of Total Phenolic Content (TPC)}

The TPC was determined by using the Folin-Ciocalteau colorimetric method presented by Singletone and Rossi (1965). One milliliter $(1 \mathrm{~mL})$ of the sample extracts was mixed with $2.5 \mathrm{~mL}$ of Folin-Ciocalteau reagent $(1: 10 \mathrm{v} / \mathrm{v})$ and left to stand for $5 \mathrm{~min}$ followed by the addition of $2.5 \mathrm{~mL}$ of $7.5 \% \mathrm{NaHCO}_{3}$ in test tubes. Standard gallic acid samples of $0,1,2,3,4,5,6 \mathrm{mg}$ were prepared from a stock solution of $1 \mathrm{mg} / \mathrm{mL}$ by pipetting $0-6 \mathrm{~mL}$ into six different test tubes. Similarly, $2.5 \mathrm{~mL}$ of FolinCiocalteau reagent and $2.5 \mathrm{~mL}$ of $\mathrm{NaHCO}_{3}$ were added in the six standard test tubes. The samples were incubated for $20 \mathrm{~min}$ at room temperature for color development. The absorbance was measured at $765 \mathrm{~nm}$ using a spectrophotometer (Thomas-Willy Laboratory mill model 4). TPC expressed as mg of GAE per g of DW sample was calculated from the standard gallic acid curve using linear equation $Y=0.739 \mathrm{x}$ (Figure 1A). TPC was finally calculated as follows:

$$
\operatorname{TPC}\left(m g G A E g^{-1}\right)=\left(\frac{C \times V}{m}\right) \times 100
$$

Where $\mathrm{C}=$ concentration of the standard solution of gallic acid; $\mathrm{V}=$ total dilution volume, and $\mathrm{m}=$ mass of sample in grams.

\section{Determination of Total Tannins Composition}

Total tannin content was determined by the spectrophotometric method described by Shrin and Prakash (2010) with minor modifications. One milliliter $(1 \mathrm{~mL})$ of the $80 \%$ methanolic extracts was mixed with $0.5 \mathrm{~mL}$ of Folin-Denis solution (1:10 $\mathrm{v} / \mathrm{v}$ ) and concentrated $\mathrm{Na}_{2} \mathrm{CO}_{3}$, and the solution was diluted to $10 \mathrm{~mL}$. A stock solution of $1 \mathrm{mg} / \mathrm{mL}$ tannic acid was prepared, and standard solutions of $0-8 \mathrm{mg}$ were prepared. The standard solutions were similarly treated as the samples, and absorbance was measured at $760 \mathrm{~nm}$ after $30 \mathrm{~min}$ of color development using a UV spectrophotometer (model: UVA 094615, England, UK). The total tannic acid content, as $\mathrm{mg} \mathrm{TAE} \mathrm{g}^{-1}$, was calculated from the standard tannic acid curve using the linear equation $Y=0.1780 \mathrm{x}$ (Figure 1B). 
TABLE 1 | List of spider plant accessions used in the study.

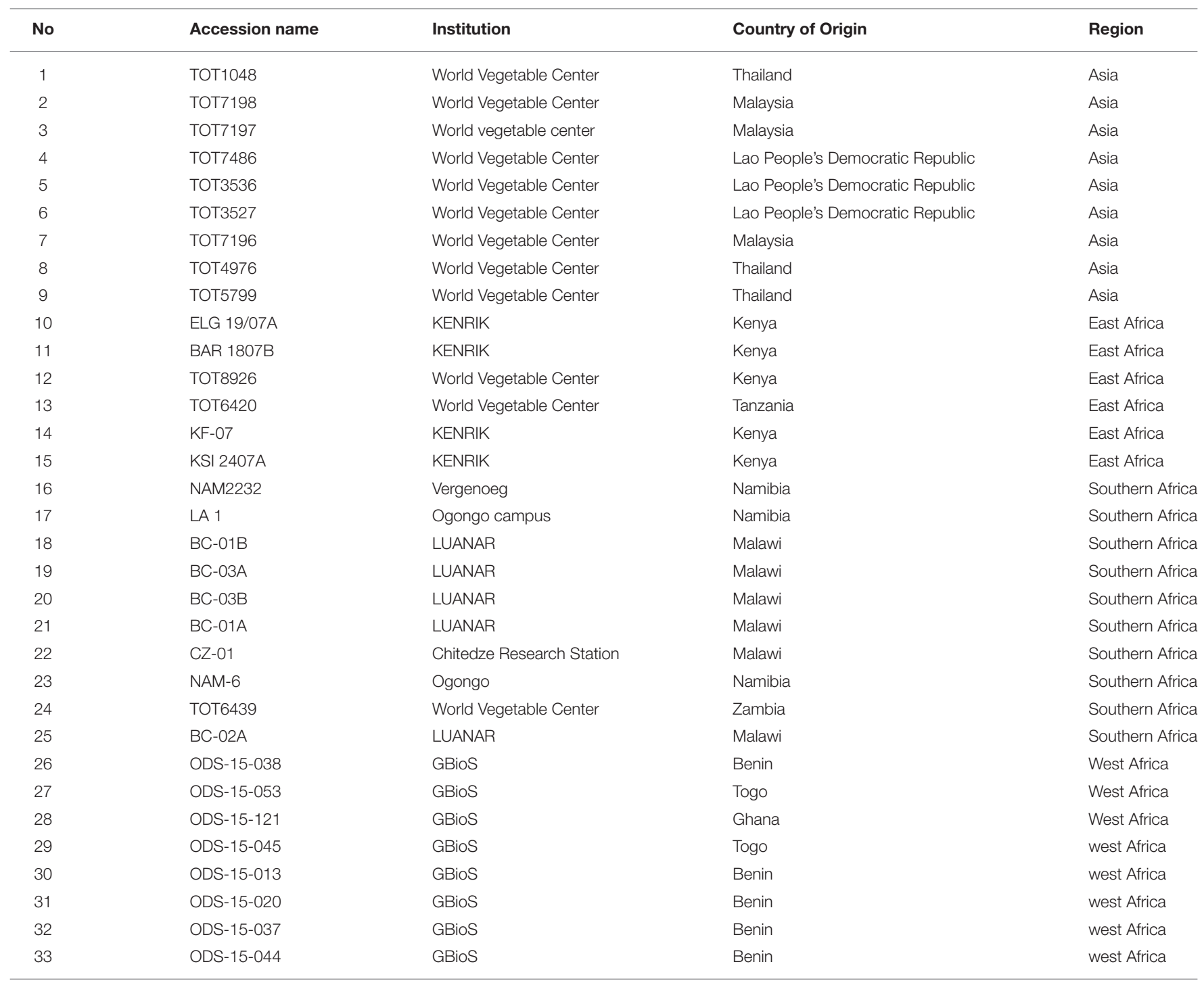

KENRIK, Kenya Resource Centre for Indigenous Knowledge; LUANAR, Lilongwe University of Agriculture and Natural Resources; GBioS, Laboratory of Genetics, Biotechnology and Seed Science.

\section{Determination of Total Anthocyanins Content by the pH Differential Method} Anthocyanins Extraction

Anthocyanins in the samples were extracted by using $80 \%$ methanol acidified with $1.5 \mathrm{M}$ hydrochloric acid $(85: 15 \mathrm{HCl}, \mathrm{v} / \mathrm{v})$ as described by Tonutare et al. (2014) with slight modification. One gram (1 g) of dry samples was placed in $100 \mathrm{~mL}$ beakers, and $10 \mathrm{~mL}$ of the solvent was added. The mixture was macerated and stirred overnight at room temperature before filtering through a Whatman no. 1 filter paper. The residues were filtered three times; then, the filtrates were combined and made up to 20 $\mathrm{mL}$ volume.

\section{Determination of Total Anthocyanins}

Total anthocyanins were determined by the $\mathrm{pH}$ differential method as outlined by Giusti and Wroltad (2001) with minor modifications. Four milliliters $(4 \mathrm{~mL})$ of the extracts were pipetted into test tubes, and solutions of $\mathrm{pH} 1.0$ (prepared from potassium chloride, $0.025 \mathrm{M}$ ) and $\mathrm{pH} 4.5$ (0.4 M Natrium/sodium acetate) were added into the different test tubes. The test tubes were let to stand for $30 \mathrm{~min}$ for color development, and absorbance was measured at 520 and $700 \mathrm{~nm}$, respectively, using a Helios spectrophotometer (Thomas-Willy Laboratory). The total anthocyanins composition was presented as cyanidin-3glucoside per gram using the following equation:

$$
T A\left(m g g^{-1}\right)=\frac{A \times M \times D F \times 1000}{[\varepsilon] \times l \times m}
$$

where $\mathrm{A}=\left(\mathrm{A}_{520}-\mathrm{A}_{700}\right)$ pH $1.0-\left(\mathrm{A}_{520}-\mathrm{A}_{700}\right) \mathrm{pH} 4.5, \mathrm{M}=$ molar mass of cyanidin-3-glucosides $(449.2 \mathrm{~g} /$ mole $), \mathrm{DF}=$ dilution factor, $1,000=$ converting grams to $\mathrm{mg}, \varepsilon=$ molar extinction coefficient /absorptivity of cyanidin-3-glucosides (26 

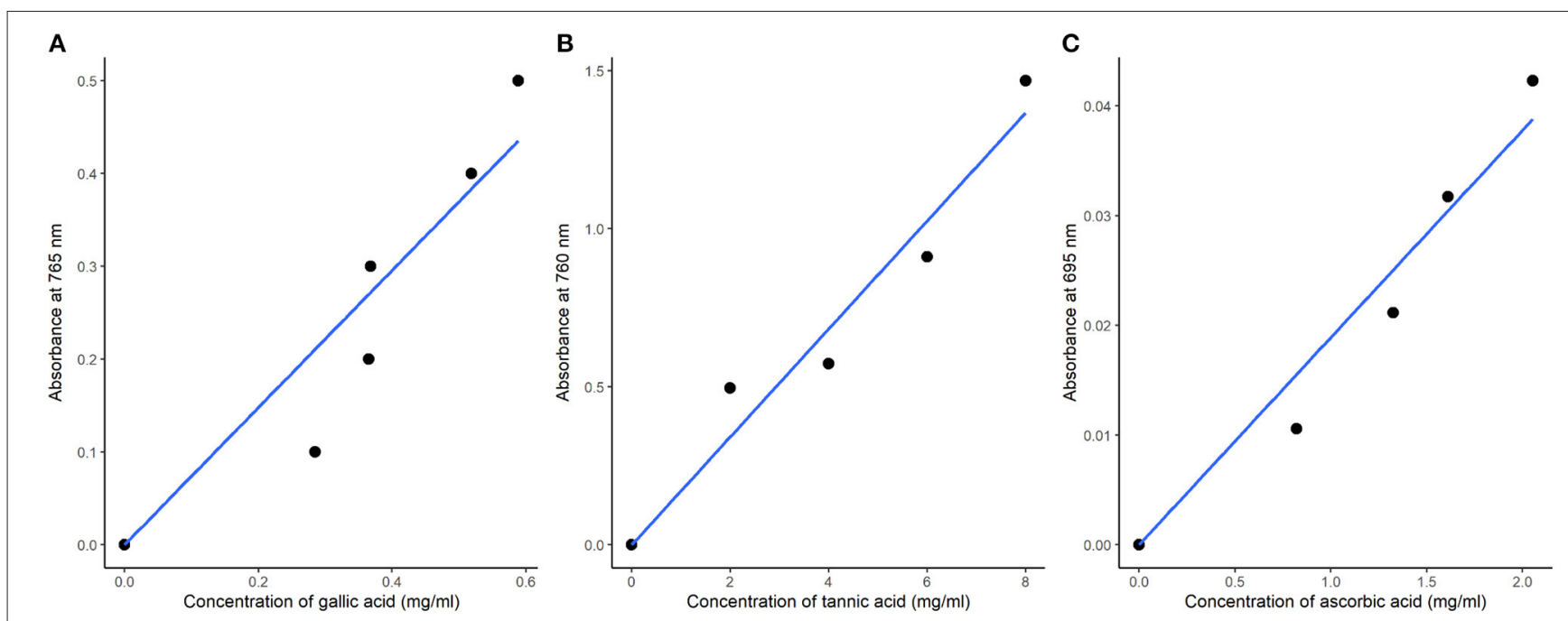

FIGURE 1 | Standard calibration curves of total phenolic compounds (A), total tannins (B), and total antioxidant activity (C) of leaves of spider plant.

$900 \mathrm{l} / \mathrm{mol} . \mathrm{cm}), \mathrm{l}=$ width of cuvette $(1 \mathrm{~cm})$, and $\mathrm{m}=$ mass of sample in grams.

\section{Determination of Total Antioxidant Activity}

Total antioxidant capacity in the plant extracts is believed to depict the combined effects of phenolics, flavonoids, and other reducing compounds and is expressed in terms of ascorbic acid equivalent (AAE) (Kumar et al., 2014). The total antioxidant activity was determined by using the phosphomolybdenum method with minor modifications (Prieto et al., 1999). The basic principle of the assay was based on the reduction of Mo (VI) to Mo (V) by the sample extracts with a subsequent formation of a green phosphate complex in an acidic condition. One milliliter $(1 \mathrm{~mL})$ of the extract was added to test tubes, with $1 \mathrm{~mL}$ of the reagents $(0.6 \mathrm{M}$ sulphuric acid, $28 \mathrm{mM}$ sodium phosphate, four $\mathrm{mM}$ ammonium molybdate), and the tubes were incubated while capped in a water bath at $95^{\circ} \mathrm{C}$ for $90 \mathrm{~min}$. Standard ascorbic acid samples of $0-6 \mathrm{mg}$ concentrations, prepared from a $1 \mathrm{mg} / \mathrm{mL}$ stock solution, were similarly treated. After cooling, the absorbance of the samples and standards was measured at $695 \mathrm{~nm}$ using a UV spectrophotometer against the blank. A standard calibration curve of ascorbic acid was plotted (Figure 1C), and total antioxidant activity was calculated as ascorbic acid equivalent (AAE) in mg AAE/g dry weight (DW).

\section{Data Analysis}

All the statistical analyses were performed using $\mathrm{R}$ software version 4.0.5 ( $\mathrm{R}$ Core Team, 2021). Descriptive statistics (minimum, maximum, range, mean, standard deviation, and coefficient of variation) were used to describe the quantitative traits, including the number of leaves and the phytochemical compounds (total phenolic acids, total tannins, total anthocyanins, and antioxidant activity). Shapiro Wilk test was used to verify the normality of the data, and none of the quantitative data was normally distributed. Consequently,
Kruskal-Wallis test was used to test the significant difference amongst the accessions and the geographical origins of the accessions. Due to the non-normality of the quantitative traits, the Spearman Rho's coefficient of correlation and their significance were performed using the function rcorr of the R package Hmisc (Harrell, 2021). Factorial analysis of mixed data (FAMD) was run on combined quantitative and qualitative traits to identify the most important components using the function $F A M D()$ of the R package FactoMineR (Lê et al., 2008). A hierarchical clustering on principal components (HCPC) based on the selected principal components was performed to cluster the accessions according to their similarities using the function $H C P C($ ) from the $\mathrm{R}$ package FactoMineR (Lê et al., 2008). Factormap of both quantitative and qualitative variables and the dendrogram were represented using the function fviz() of the factoextra package (Kassambara and Mundt, 2021).

\section{RESULTS}

\section{Dietary Phytochemical Content in Different Accessions of Spider Plant}

The dietary phytochemical content in leaves of vegetables is an indicator of its potential to provide nutritional and health benefits when utilized. The total phenolic content (TPC), expressed as gallic acid equivalent per gram of dry weight (GAE/g DW) in spider plant extracts, ranged from $64.7 \mathrm{mg}$ GAE/g DW in TOT8926 to $270.7 \mathrm{mg}$ GAE/g DW in ODS-15-053 (Table 2; Figure 2A). The total tannin content ranged from 41.1 to $466.3 \mathrm{mg}$ TAE/g DW, while the total anthocyanin contents were in the ranges between 10.8 and $126.9 \mathrm{mg}$ cyanidin-3-glucoside/g DW. The spider plant extracts exhibited the mean antioxidant activity of $315.3 \mathrm{mg}$ AAE/100 $\mathrm{g}$ DW and were within the range of 189.9 to $492.3 \mathrm{mg}$ AAE/g DW.

There were significant differences in TPC, total tannins, and total anthocyanins amongst spider plant accessions $(p<0.001)$ (Figures 2A,C,E). ODS-15-053 had the highest TPC (270.7 mg 
TABLE 2 | Descriptive statistics for dietary phytochemicals and morphological traits of the 33 accessions of Gynandropsis gynandra.

\begin{tabular}{|c|c|c|c|c|c|c|}
\hline Traits & Min & Max & Range & Mean & SD & CV (\%) \\
\hline Total phenolic compounds (mg GAE/g DW) & 64.7 & 270.7 & 206.0 & 123.3 & 41.6 & 33.8 \\
\hline Total tannins (mg TAE/g DW) & 41.1 & 466.3 & 425.2 & 190.1 & 105.5 & 55.5 \\
\hline Total anthocyanins (mg cyanidin-3-glucoside/g DW) & 10.8 & 126.9 & 116.1 & 46.0 & 28.2 & 61.4 \\
\hline Antioxidant activity (mg AAE/100 g DW) & 189.2 & 492.3 & 303.2 & 315.3 & 70.3 & 22.3 \\
\hline Number of leaves & 12.3 & 142.0 & 129.7 & 46.3 & 28.8 & 62.2 \\
\hline
\end{tabular}

GAE, gallic acid equivalent; TAE, tannic acid equivalent; $A A E$, ascorbic acid equivalent; DW, dry weight; SD, standard deviation; CV, coefficient of variation.

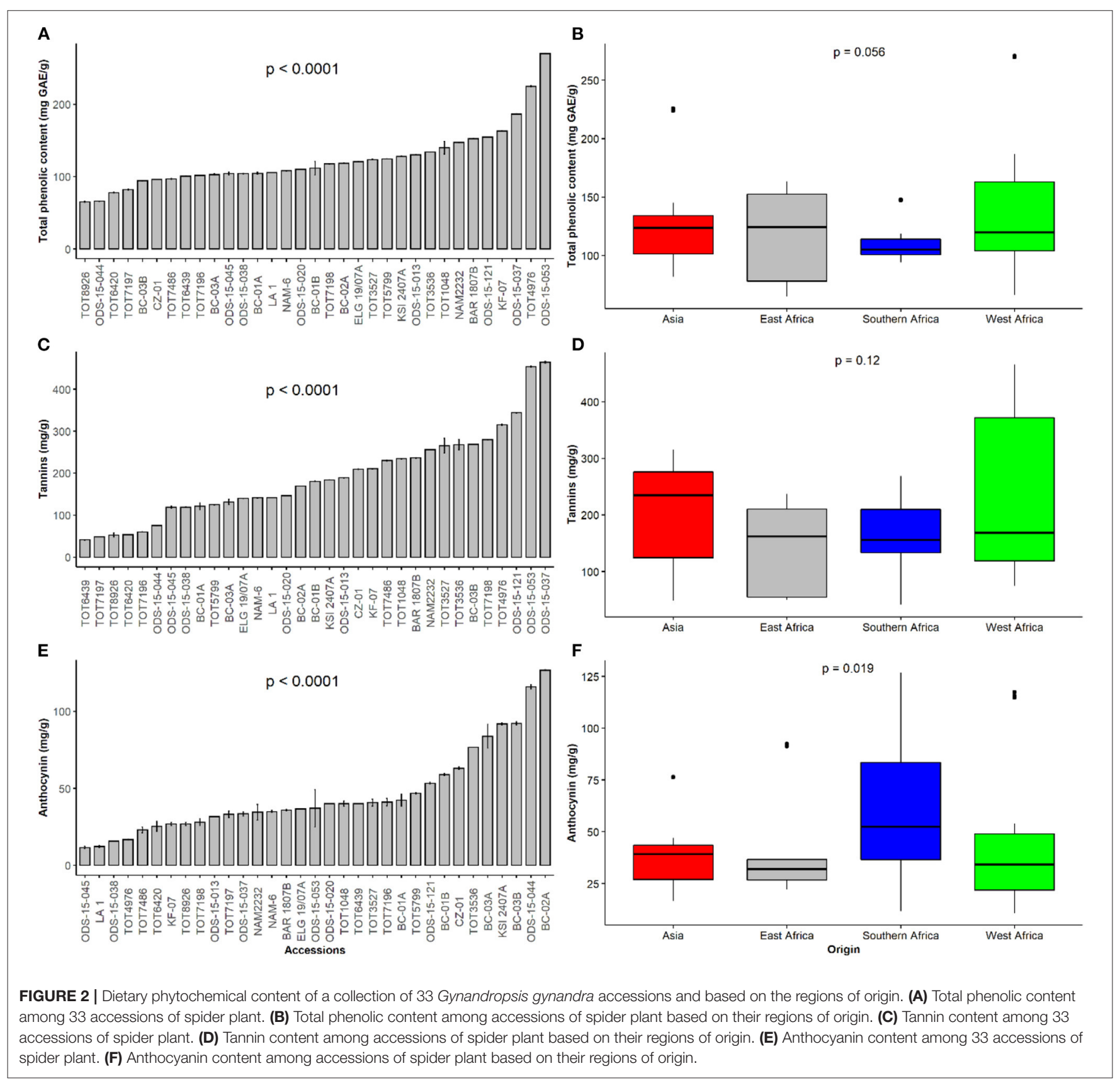



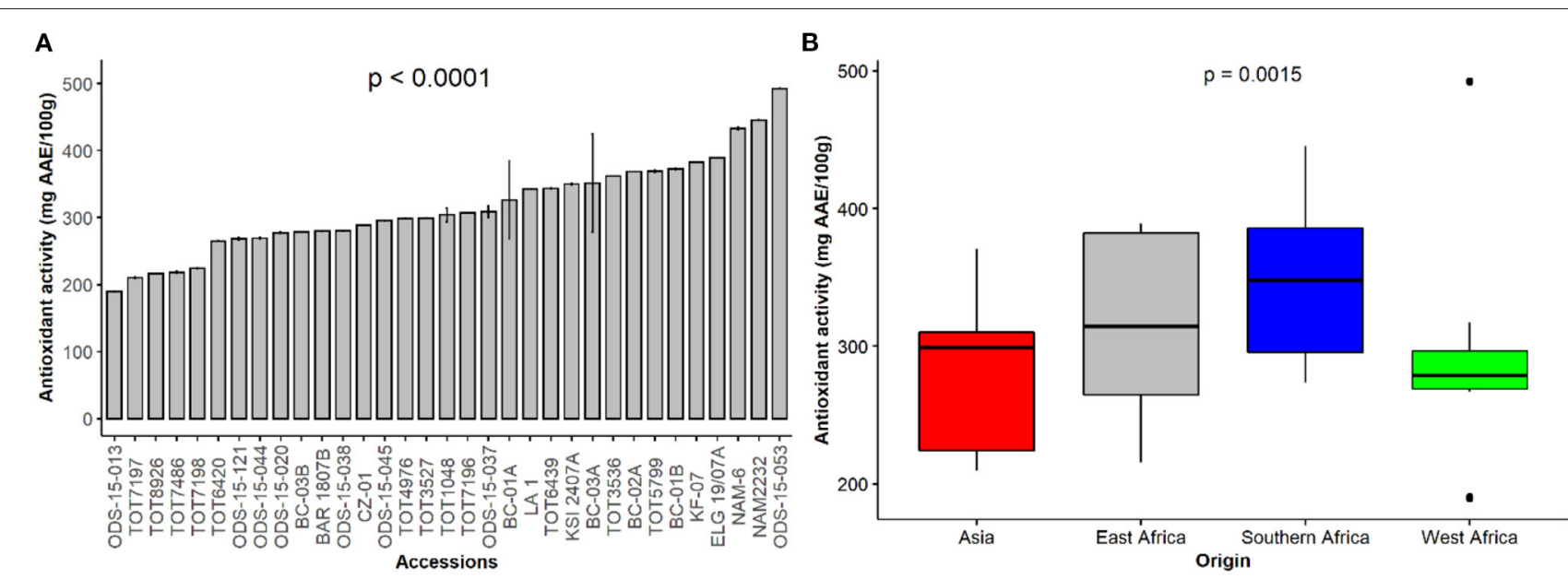

FIGURE 3 | Antioxidant activity of individual accessions (A) and based on their regions of origin (B) of a collection of 33 Gynandropsis gynandra accessions.

GAE/g DW), while TOT8926 had the least TPC (64.7 mg GAE/g DW). Fourteen spider plant accessions, representing $42.4 \%$, had TPC below the overall mean of $190.1 \mathrm{mg}$ GAE/g DW. The other accessions which contained high quantities of TPC were TOT4976 (225 mg GAE/g DW) and ODS-15-037 (187 mg GAE/g DW). The differences were not significant across the regions. However, the results showed wide variation in East Africa and West Africa, while southern Africa had low levels with narrow variability (Figure 2B).

Total tannin content was the highest in ODS-15-037 (464 mg TAE/g) and the lowest in TOT6439 (41 mg TAE/g DW) (Figure 2C). In addition to ODS-15-037, the other superior spider plant accessions (ODS-15-053, ODS-15-121, and TOT4976) showed high amounts of total tannins. Although a comparison of total tannin content across regions did not show significant differences, accessions from Asia had a higher median while those from West Africa contained some individuals with the highest content of total tannins (Figure 2D).

Total anthocyanin content significantly differed across the accessions $(p<0.001)$ (Figure 2E). Total anthocyanin content was the highest in BC-02A, followed by ODS-15-044, while ODS-15-045 had the lowest level. Accessions originating from southern Africa were characterized by significantly high levels of anthocyanins $(p<0.05)$, while the rest of the regions did not show statistical differences (Figure 2F). East African accessions had the lowest variation of anthocyanin content seconded by accessions from Asia.

\section{Antioxidant Activity of Spider Plant Accessions}

The antioxidant activity in vegetable plants indicates the availability of specific elements that scavenge free oxygen and nitrogen radicals. Figure 3A depicts the antioxidant activity, expressed as ascorbic acid equivalent (AAE) per $100 \mathrm{~g}$ dry weight (DW) of the spider plant accessions used in this study and the antioxidant activity across the regions of origin (Figure 3B). ODS015-053 (492.2 mg AAE/100 g DW), NAM2232
(445.3 mg AAE/100 g DW) and NAM6 (432.5 mg AAE/100 g DW) exhibited the highest levels of antioxidant activity, while ODS-15-013 had the lowest antioxidant activity $(p<$ 0.001). Regional comparisons suggested accessions originating from southern Africa had high antioxidant activity $(177.5 \mathrm{mg}$ AAE/100g DW) seconded by accessions from east Africa. In contrast, accessions originating from Asia had the lowest antioxidant activity (Figure 3B).

\section{Relationships Amongst Dietary Phytochemicals and Morphological Attributes of Spider Plant Accessions}

The number of leaves significantly varied amongst spider plant accessions and across regions of origin $(p<0.001)$ (Figures 4A,B). ODS-15-045 produced the highest number of leaves, while TOT7197 had the least. Comparison based on regions showed that accessions from West Africa produced the highest mean number of leaves while the Asian accessions had the least.

There was no relationship, however, between the level of the dietary phytochemicals and the number of leaves (Table 3). A significant and positive association was observed between TPC and total tannins $(r=0.73)$ and between TPC and antioxidant activity $(r=0.44)$ (Table 3$)$.

A two-dimensional factor map of both qualitative and quantitative traits positioned tannins and TPC close to stem color, anthocyanins close to leaf color, while antioxidant activity was associated with leaf trichomes and number of leaves (Figure 5).

On the other hand, the hierarchical clustering on the results of the factorial analysis of mixed data (both quantitative and qualitative traits) grouped the 33 accessions of spider plant into five groups (Figure 6) with their characteristics presented in Table 4.

Cluster C1 was characterized by low TPC and tannin content and high antioxidant activity. The cluster C2 had only one 

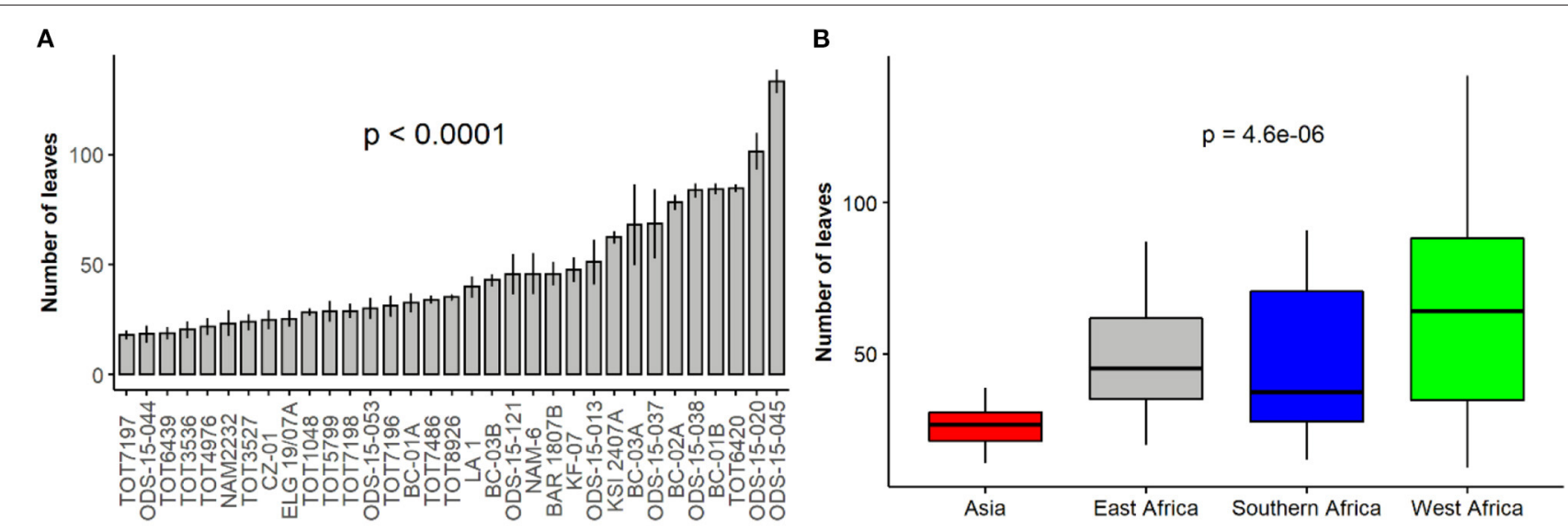

FIGURE 4 | Variation in the number of leaves among 33 accessions (A) and based on their regions of origin (B) of a collection of Gynandropsis gynandra.

TABLE 3 | Spearman rank phenotypic correlation between phytochemicals and number of leaves of 33 accessions of Gynandropsis gynandra.

\begin{tabular}{lcccc}
\hline & TPC & Tannins & Anthocyanin & Antioxidant activity \\
\hline Tannins & $0.73^{\star \star \star}$ & & & \\
Anthocynin & -0.03 & 0.08 & & \\
Antioxidant activity & $0.44^{\star}$ & 0.12 & 0.26 & -0.04 \\
Number of leaves & 0.01 & -0.05 & -0.15 & \\
\hline
\end{tabular}

${ }^{\star},{ }^{* \star *}$ significant at probability levels of 0.05 and 0.001 , respectively.

accession from West Africa with a low antioxidant activity and a high number of leaves. Clusters C3 and C4 had moderate TPC, tannins, antioxidant activity, and number of leaves, but they were distinct for anthocyanin content (cluster C3 and C4 had high and low anthocyanin content, respectively). Lastly, cluster C5 was characterized by high TPC, tannin content, and antioxidant activity with low number of leaves.

\section{DISCUSSION}

\section{Phytochemical Content in Different Accessions of Spider Plant}

Dietary phytochemicals are bioactive nutrient plant chemicals that play a role in providing desirable health benefits beyond basic nutrition, thereby reducing the risk of major chronic diseases (Liu, 2004). Vitamins, such as vitamins A, C, and E (Sarker and Oba, 2020b), some enzymes (Sarker and Oba, 2018b,c), and phytochemicals, such as pigments, phenolic, and flavonoid compounds, act as antioxidants (Sarker et al., 2018b, 2020a,b; Sarker and Oba, 2020a,d). These antioxidants neutralize/scavenge free oxygen and nitrogen radicals and prevent many diseases in the human body (Sarker and Oba, 2018e). Dietary phytochemicals of leafy vegetables, i.e., phenolics, are versatile compounds, such as phenol, coumarins, different groups of phenolic acids, and different groups of flavonoids, including flavonols, flavones, flavanols, flavanones, anthocyanins, chalcones, and different groups of non-flavonoids, including tannins, lignans and stilbenes that have been reported to have important antioxidant properties (Meda et al., 2013; Sarker and Oba, 2020e,f). The phytochemicals are distributed widely and occur in different concentrations within and across plant species. This study identified accessions of spider plant that contain high levels of TPC, total tannins, and anthocyanins. Based on our findings, as evidenced by the high levels obtained, these accessions are potential candidates for use in breeding programs aimed at enhancing the nutraceutical value of spider plant. For example, ODS-15-053, which had high levels of TPC, can be used as a parent in breeding programs that are aimed at enhancing the potential of spider plant in treating non-communicable diseases, including hypertension, diabetes, cancer, and other cardiovascular diseases, as previously reported by different researchers (Kumari and Jain, 2012; Kutsututsa et al., 2014). In addition, phenolic compounds are reported to play essential roles in defense mechanisms against pathogens, parasites, and predators of plants, suggesting that the accessions that have a high content of phenolic compounds could be possible sources of genes for insect pests resistance. In this study, the mean of TPC of the spider plant accessions (123.3 mg GAE/g) was higher than the values reported by Jiménez-Aguilar and Grusak (2017), but lower than the findings of Meda et al. (2013), who reported $133.0 \mathrm{mg} \mathrm{GAE} / \mathrm{g}$. In addition, other authors found lower levels of TPC (Somers et al., 2020), which were comparable to some African vegetables (Jiménez-Aguilar and Grusak, 2015). These authors used a small sample size and different extraction methodologies, which might account for the differences.

This study showed the diversity of TPC across accessions (66.0 to $270.0 \mathrm{mg} \mathrm{GAE} / \mathrm{g}$ ) and regions (108.9 to $140.8 \mathrm{mg} \mathrm{GAE} / \mathrm{g}$ ), suggesting both genetic and environmental effects on TPC. The gallic acid equivalent diversity in TPC across the genotypes of leaf vegetable amaranth species, such as Amaranthus blitum (Sarker and Oba, 2020c), weedy species (Sarker and Oba, 2019b), green morph amaranth (Sarker et al., 2020a,b), and red morph amaranth (Sarker and Oba, 2019c) were reported, which conform with the present findings. The differences in TPC and diversity 


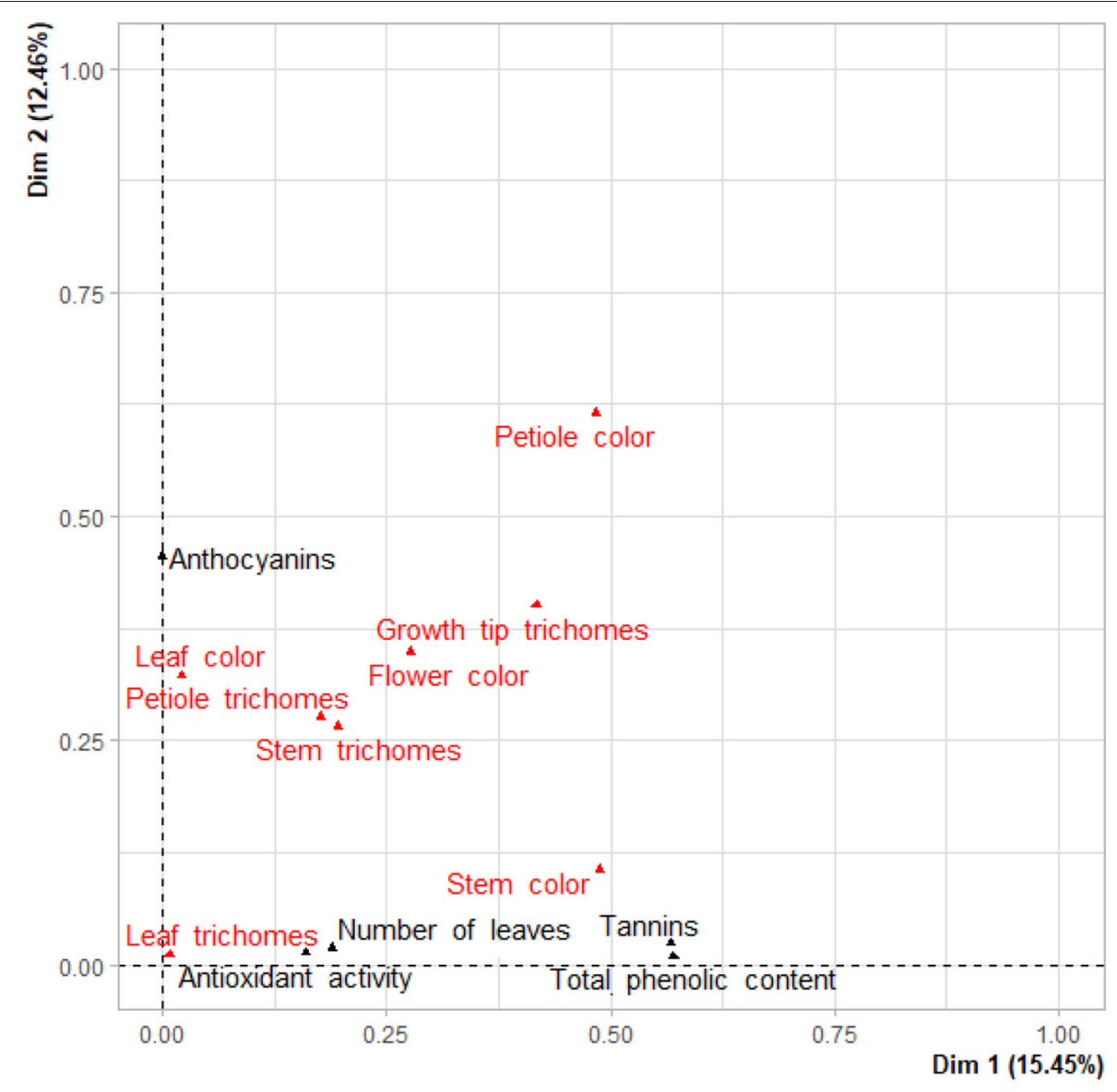

FIGURE 5 | Factor map positioning qualitative (in red) and quantitative (in black) variables on first and second components.

in the functions of dietary phytochemicals both in human health and in plant defense offer opportunities for using the identified superior accessions as candidates for pyramiding genes of multiple traits in breeding programs. However, there is a need to identify specific phenolic compounds responsible for specific functions and the location and mode of inheritance of these potential genes to enable effective and efficient breeding.

Tannins are another category of dietary phytochemicals that are reported to accelerate blood clotting, reduce blood pressure, decrease the serum lipid level, produce liver necrosis, and modulate immune responses, amongst other functions (Chung et al., 1998). Negative health effects have also been reported and are dependent on the intake levels (Chung et al., 1998). This study identified spider plant accessions with high levels of tannins (ODS-15-037) as well as accessions with low levels of tannins such as TOT6439. This implies that accessions in both extremes could be useful in breeding programs with different objectives. For example, Chung et al. (1998) reported some incidences of esophageal cancer emanating from eating tannin-rich foods such as betel nuts and herbal teas. However, the same authors were quick to indicate that the carcinogenic activity observed might be related to components associated with the tannins rather than the tannins themselves. Further studies would, therefore, be required to determine the levels of tannins that could be used to satisfy or accomplish specific objectives. Tannins have the potential of being anticarcinogenic and antimutagenic due to their anti-oxidative properties, which protect against cellular oxidative damage (Chung et al., 1998). However, a weak relationship of tannin levels with antioxidant activity was detected in this study. This could be due to different levels of the different types of tannins that might have been present in the extracts. Tannins are classified as hydrolyzable (Ashok and Upadhyaya, 2012); however, condensation of phenolic compounds results in tannins (Ghosh, 2015). The strong and significant correlation between total phenolic compounds and total tannins observed in this study, therefore, might imply the presence of condensed tannins in the total tannin extracts. These findings agree with other researchers who reported that spider plant contain high levels of condensed tannins (Kutsututsa et al., 2014). Furthermore, condensed tannins are reported to have strong antioxidant activity with high therapeutic potential (Haslam, 1966; Ghosh, 2015). Nevertheless, this study detected a relatively weak correlation between total tannins and antioxidant activity, thus suggesting the need for further studies to determine the levels and antioxidant activities of the different types of tannins in spider plant. Additionally, the presence of tannins was 


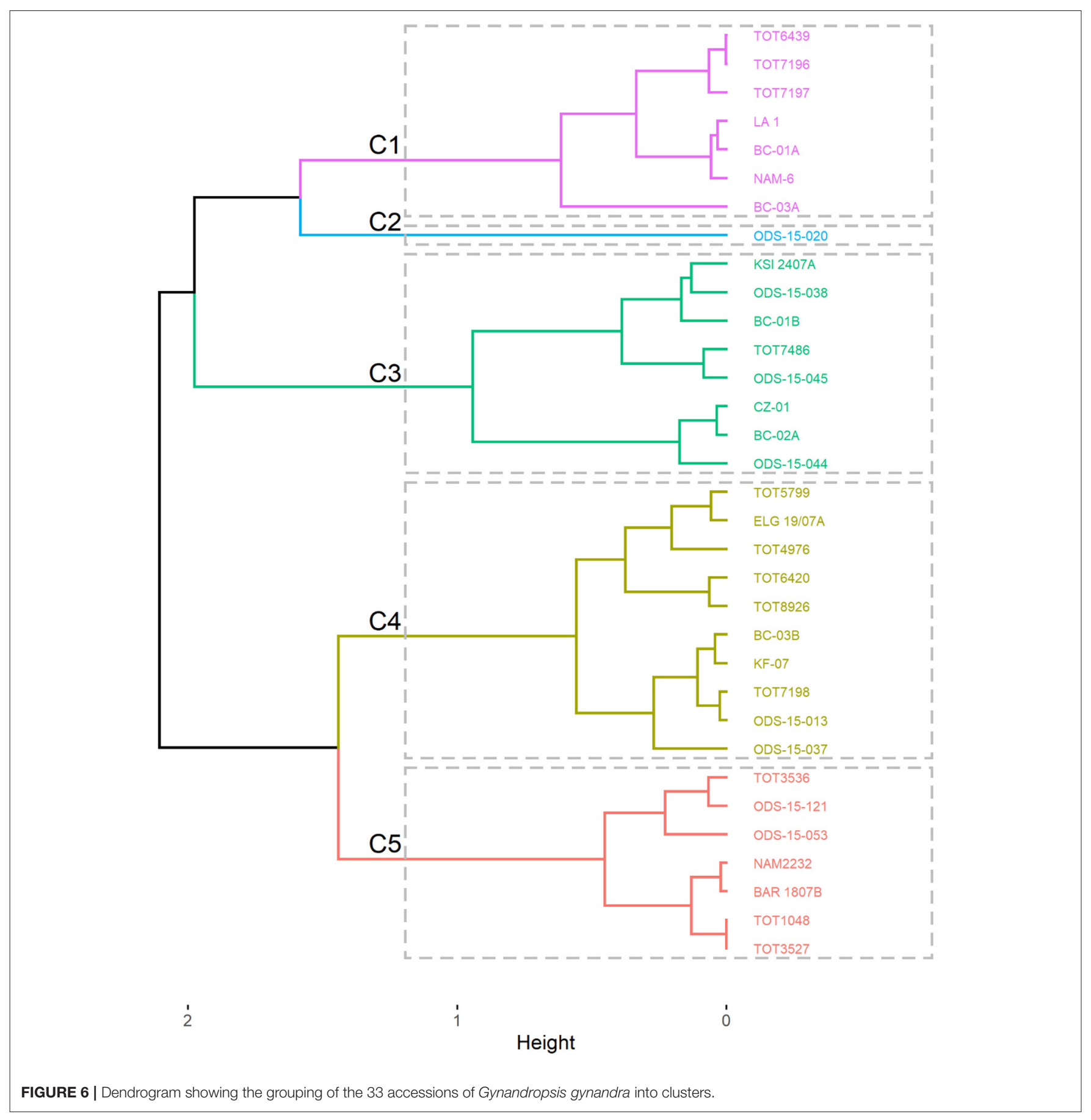

reported to be responsible for the astringent taste (Kutsututsa et al., 2014) and influenced the palatability and utilization of the vegetable (Chataika et al., 2020). Identifying specific types of tannins and their antioxidant potential in different accessions of spider plant would therefore aid in targeted nutraceutical breeding for addressing specific human health and nutrition disorders and genetic improvements in the species.

Another dietary phytochemical that has been reported to affect palatability in spider plant is anthocyanin, which is believed to be responsible for the purple color of the different plants (Mueller-Harvey, 2001; Dasgupta and De, 2007; Gonzali and Perata, 2020). Furthermore, anthocyanins have been reported as having the capacity of lowering the risk of cardiovascular diseases, cancer, neurodegenerative disorders, and bone loss associated with aging (Chen et al., 2021; Hair et al., 2021), as well as lowering blood pressure, improving visual acuity, and preventing diabetes (Rozita et al., 2018). The accessions with the highest levels of anthocyanins were in cluster C3 
TABLE 4 | Dietary phytochemicals and number of leaves differentiation among spider plant accession clusters.

\begin{tabular}{lccccc}
\hline Clusters & TPC & Tannins & Anthocyanin & $\begin{array}{c}\text { Antioxidant } \\
\text { activity }\end{array}$ & $\begin{array}{c}\text { Number } \\
\text { of leaves }\end{array}$ \\
\hline C1 & 100.7 & 97.8 & 41.1 & 330.5 & 36.3 \\
C2 & 109.9 & 146.7 & 40.1 & 277.3 & $\mathbf{1 0 1 . 5}$ \\
C3 & 103.2 & 160.8 & $\mathbf{6 3 . 3}$ & 305.3 & 64.9 \\
C4 & 130.5 & 209.8 & 36.5 & 292.1 & 43.5 \\
C5 & $\mathbf{1 6 0 . 3}$ & $\mathbf{2 9 4 . 0}$ & $\mathbf{4 5 . 4}$ & $\mathbf{3 5 0 . 1}$ & 31.1 \\
\hline
\end{tabular}

Values in bold are for high values characterizing the cluster.

and included BC-02A, ODS-15-044, BC-03B, and KSI-2407. This could be because of the diversity of the levels of these phytochemicals in different accession and across the regions of origin. The identification of superior accessions with high levels of both anthocyanins and tannins does not suggest any linkage of the genes controlling these traits, but another factor might be playing a role. One factor that could have been responsible for this observation is the agro-ecological factors associated with the regions of origin. This was evidenced by the significantly high anthocyanin content in Southern African accessions, while accessions from West Africa had high TPC and tannins. In addition, Adeka et al. (2019) reported significant changes in the levels of the bitterness of spider plant from different agro-ecologies, suggesting changes in anthocyanin levels due to agro-ecological factors. The observations suggest an opportunity for managing the levels of anthocyanin, including palatability, by changing specific environmental factors. This calls for further investigation to determine the specific environmental factors that affect the levels of anthocyanin and the extent of environmental influence.

\section{Antioxidant Activity of Different Accessions of Spider Plant}

Antioxidant activity, expressed as ascorbic acid equivalent (AAE), is believed to be a better way of depicting the combined effect of free radical scavenging phytochemicals in the plant extracts. The antioxidant activity of the spider plant accessions ( 189.2 to $492.3 \mathrm{mg}$ of $\mathrm{AAE} / 100 \mathrm{~g}$ ) was slightly lower than what other authors found (Stangeland et al., 2009; Jiménez-Aguilar and Grusak, 2015; Somers et al., 2020). The variations in antioxidant activity across different leafy vegetable amaranth species (Sarker et al., 2018b,c; Sarker and Oba, 2019a) were reported, which conform with the present findings. Stangeland et al. (2009) reported antioxidant activity of $390 \mathrm{mg}$ TE/100 g in spider plant, which was higher than the 35 Ugandan fruits and vegetables that were included in their study. Although the average antioxidant activity was lower (315.3 mg AAE/100 g) than what was reported by other authors, individual accessions with higher antioxidant activities, such as ODS-15-053 (492.2 mg AAE/100g) and NAM2232 (445.3 mg AAE/100 g), were identified as candidates for breeding programs aimed at improving antioxidant activity of spider plant. These findings suggest the potential use of the spider plant accessions as a vegetable to provide the health benefits associated with antioxidant activity as well as the use of the superior accessions as donor parents in improving antioxidant activity.

Antioxidants are reported to protect cells from oxidative damage caused by free radicals, which can accumulate in the body due to diseases and exposure to chemicals, amongst other causes. Several studies suggest a close link between oxidative stress and the development of diseases such as cancer, AIDS, cardiovascular disease, diabetes, hypertension, inflammatory conditions, and neurodegenerative disorders (Stangeland et al., 2009; Kamble and Gacche, 2019). Furthermore, the antioxidants are reported to reduce DNA damage (Sevgi et al., 2015) and are believed to have antiaging and vitality strengthening properties (Giri et al., 2017). The results from this study suggest that the spider plant is a source of antioxidants, and this supports its use in traditional medicine (Chataika et al., 2020). Sowinmi and Afolayan (2015) also observed that G. gynandra possessed high secondary metabolites, which accounted for its strong antioxidant ability, thus justifying its use as naturally occurring antioxidants in folkloric medicine. The identification of G. gynandra with strong antioxidant ability availed an opportunity for targeted seed multiplication for conservation and sustainable use as a relish, dietary supplements, and for commercial purposes. Commercial production of the identified G. gynandra species, including the development of nutraceutical products, would potentially pave the way for deriving monetary benefits and economic betterment of the involved communities.

Accessions in cluster C5 are good candidates for the breeding program and cultivar release. They combine high levels of total phenolic, tannins, and antioxidant activity. This was further illustrated by the significant positive correlation among total phenolic, tannins, and antioxidant activity. This finding might suggest the possible control of these phytochemicals by a group of genes. Further investigations should focus on determining environmental factors influencing these phytochemicals and genes controlling them through the development of mapping populations. The development of the mapping population should consider the individuals from clusters $\mathrm{C} 2$ and $\mathrm{C} 3$, as they are characterized by high anthocyanin content and the number of leaves, respectively.

\section{CONCLUSION}

Results from this study have revealed that G. gynandra accessions contain high levels of dietary phytochemicals, which account for their strong antioxidant ability. The key phytochemicals in spider plant were the TPC, tannins, and anthocyanins. These phytochemicals vary in amounts in different accessions and are associated with the geographical origin of the spider plant accessions. It might be possible to identify candidate accessions for use in breeding programs aimed at improving the nutraceutical quality of the species. Plant breeders implementing breeding initiatives for managing lifestyle diseases associated with oxidative stress, including cancer, cardiovascular diseases, diabetes, and neurodegenerative disorders, can use these superior 
spider plant accessions as parental genotypes for crosses and for large-scale cultivation. The findings from this study provide science-based solid evidence in advocating for regular consumption of spider plant in order to minimize oxidative stress-related diseases. However, more studies are strongly recommended to dissect the genetic and environmental components affecting the inheritance of the phytochemicals to be able to develop a robust breeding program that would optimize the transfer and fixing of specific nutraceutical traits.

\section{DATA AVAILABILITY STATEMENT}

The original contributions presented in the study are included in the article/supplementary material, further inquiries can be directed to the corresponding author.

\section{AUTHOR CONTRIBUTIONS}

BC: conceptualization of the design of the research and the methodology, investigation, data curation, analysis, and drafted the original manuscript. AH: data analysis, reviewing the results, and editing the manuscript. LA, EA-D, and JS: review of the

\section{REFERENCES}

Adeka, R., Lukhoba, C., Odhiambo, J., and Maundu, P. (2019). Morphological traits as indicators of bitterness in traditional vegetables: the case of spider plant (Gynandropsis gynandra) in Kenya. Asian J. Res. Bot. 2, 1-15. Available online at: https://www.journalajrib.com/index.php/AJRIB/article/view/30070

Adhikari, P. P., and Paul, S. B. (2018). Medicinally important plant Cleome gynandra: a phytochemical and pharmacological explanation. Asian J. Pharm. Clin. Res. 11, 21-29. doi: 10.22159/ajpcr.2017.v11i1.22037

Anbazhagi, T., Kadavul, K., Suguna, G., and Petrus, A. J. A. (2009). Studies on the pharmacognostical and in vitro antioxidant potential of Cleome gynandra Linn. leaves. Nat. Prod. Radiance 8, 151-157. Available online at: http://nopr.niscair. res.in/handle/123456789/4036

Anderson, R. A., and Polansky, M. M. (2002). Tea enhances insulin activity. J. Agri. Food Chem. 50, 7182-7186. doi: 10.1021/jf020514c

Ashok, P. V., and Upadhyaya, K. (2012). Tannins are Astringent. J. Pharmacognosy Phytochem. 1, 45-50. Available online at: www.phytojournal.com

Bala, A., Kar, B., Haldar, P. K., Mazumder, U. K., and Bera, S. (2010). Evaluation of anticancer activity of Cleome gynandra on ehrlich's ascites carcinoma treated mice. J. Ethnopharmacol. 129, 131-134. doi: 10.1016/j.jep.2010.03.010

Chakrabarty, T., Sarker, U., Hasan, M., and Rahman, M. (2018): Variability in mineral compositions, yield and yield contributing traits of stem amaranth (Amaranthus lividus). Genetika 50, 995-1010. doi: 10.2298/GENSR1803995C

Chataika, B., Akundabweni, L., Achigan-Dako, E., Sibiya, J., and Kwapata, K. (2020). Utilization of spider plants (Gynandropsis gynandra, L. Briq) amongst farming households and consumers of Northern Namibia. Sustainability 12:6604. doi: 10.3390/su12166604

Chaves, N., Santiago, A., and Alias, J. C. (2020). Quantification of the antioxidants of plant extracts: analysis of sensitivity and hierarchization based on the method used. Antioxidants 9:76. doi: 10.3390/antiox9010076

Chen, J., Xu, B., Sun, J., Jiang, X., and Bai, W. (2021). Anthocyanin supplement as a dietary strategy in cancer prevention and management: a comprehensive review. Crit. Rev. Food Sci. Nutr. 1, 1-13. doi: 10.1080/10408398.2021.1913092

Chepkwony, C. I., Cherutoi, K. J., Munyendo, L. W., and Amdany, R. (2020). Antioxidant and free radical scavenging activities of selected Kenyan leafy vegetables. AER J. 4, 92-102. Available online at: http://www.aer-journal.info methodology and results, supervision of the research, and editing of the manuscript. KM: supervised the laboratory work, reviewed, and edited the manuscript. All authors have read and agreed to the published version of the manuscript.

\section{FUNDING}

The Intra-Africa Academic Mobility Scheme of the European Union (EU) funded this work as part of the Ph.D. research of the first author under the project grant number 20162988 on Enhancing training and research mobility for novel crops breeding in Africa (MoBreed) through the Education, Audiovisual and Culture Executive Agency (EACEA).

\section{ACKNOWLEDGMENTS}

The support rendered by Wilson Nkhata, Lonely Chataika, and technicians from the Lilongwe University of Agriculture and Natural Resources in preparing the samples is highly appreciated. Special thanks go to Lesten E.C. Chatepa, the technician at the Basic Science Department, Lilongwe University of Agriculture and Natural Resources, who assisted with all the analytical protocols and processes.

Chung, K. T., Wong, T. Y., Wei, C., Huang, Y. W., and Lin, Y. (1998). Tannins and human health: a review. Crit. Rev. Food Sci. Nutr. 38, 421-464. doi: 10.1080/10408699891274273

Chweya, J. A., and Mnzava, N. A. (1997). Cat's whiskers. (Cleome gynandra L.) Promoting the conservation and use of underutilized and neglected crops. Rome: Institute of Plant Genetics and Crop Plant Research. 1-54.

Das, L., Bhaumik, E., Raychaudhuri, U., and Chakraborty, R. (2012). Role of nutraceuticals in human health. J. Food Sci. Technol. 49, 173-183. doi: 10.1007/s13197-011-0269-4

Dasgupta, N., and De, B. (2007). Antioxidant activity of some leafy vegetables of india: a comparative study. Food Chem. 101, 471-474. doi: 10.1016/j.foodchem.2006.02.003

Ghosh, D. (2015). Tannins from foods to combat diseases. Int. J. Pharma Res Rev. 5, 40-44. Available online at: https://www.researchgate.net/publication/ 277029056

Giri, L., Belwal, T., Bahukhandi, A., Suyal, R., Bhatt, I. D., Rawal, R. S., et al. (2017). Oxidative DNA damage protective activity and antioxidant potential of Ashtvarga species growing in the Indian Himalayan Region. Ind. Crops Prod. 102, 173-179. doi: 10.1016/j.indcrop.2017. 03.023

Giusti, M. M., and Wroltad, R. E. (2001). Characterization and measurement of anthocyanins by UV-visible spectroscopy. Curr. Protoc. Food Anal. Chem. 1, 1-13. doi: 10.1002/0471142913.faf0102s00

Gonzali, S., and Perata, P. (2020). Anthocyanins from purple tomatoes as novel antioxidants to promote human health. Antioxidants 9:1017. doi: 10.3390/antiox9101017

Hair, R., Sakaki, J. R., and Chun, O. K. (2021). Anthocyanins, microbiome and health benefits in aging. Molecules 26:537. doi: 10.3390/molecules26030537

Harrell, F. J. (2021). Package "Hmisc." Available online at: https://cran.r-project. org/web/packages/Hmisc/Hmisc.pdf (accessed June 25, 2021).

Haslam, E. (1966). Types of Tannic Acid, Chemistry of Vegetable Tannins. Vol. 19 London: Academic Press.

Jiménez-Aguilar, D. M., and Grusak, M. A. (2015). Evaluation of minerals, phytochemical compounds and antioxidant activity of Mexican, Central American, and African green leafy vegetables. Plant Foods Hum. Nutr. 70, 357-364. doi: 10.1007/s11130-015-0512-7 
Jiménez-Aguilar, D. M., and Grusak, M. A. (2017). Minerals, vitamin C, phenolics, flavonoids and antioxidant activity of Amaranthus leafy vegetables. J. Food Compost. Anal. 58, 33-39. doi: 10.1016/j.jfca.2017.01.005

Kamble, S. S., and Gacche, R. N. (2019). Evaluation of anti-breast cancer, antiangiogenic and antioxidant properties of selected medicinal plants. Eur. J. Integr. Med. 25, 13-19. doi: 10.1016/j.eujim.2018.11.006

Kassambara, A., and Mundt, F. (2021). Factoextra: Extract and Visualize the Results of Multivariate Data Analyses. R package version 1.0.7. Available online at: https://CRAN.R-project.org/package=factoextra (accessed April 4, 2021).

Keleş, D., Özgen, S., and Saraçoglu, O., Ata, A., and Özgen, M. (2016). Antioxidant potential of Turkish pepper (Capsicum annuum L.) genotypes at two different maturity stages. Turk. J. Agric. For. 40, 542-551. doi: 10.3906/tar-1601-24

Kumar, S., Sanfhir, R., and Ojha, S. (2014). Evaluation of antioxidant activity and total phenol in different varieties of Lantana camara leaves. BCM Res Notes 7:560. doi: 10.1186/1756-0500-7-560

Kumari, M., and Jain, S. (2012). Tannins: an antinutrient with positive effect to manage diabetes. Res. J. Recent Sci. 1, 1-8. Available online at: www.isca.in

Kutsututsa, R. T., Gasura, E., Mabasa, S., and Ngadze, E. (2014). Variability in condensed tannins and bitterness in spider plant genotypes. Afr. Crop Sci. 22, 275-280. Available online at: https://www.ajol.info/index.php/acsj/article/ view/110404

Lê, S., Josse, J., and Husson, F. (2008). FactoMineR: an R package for multivariate analysis. J. Stat. Softw. 25, 1-18. doi: 10.18637/jss.v025.i01

Liu, R. H. (2004). Potential synergy of phytochemicals in cancer prevention: mechanism of action. J. Nutr. 134, 3479S-3485S. doi: 10.1093/jn/134.12.3479S

Meda, N. T. R..., Bangou, M. J., Bakasso, S., Millogo-Rasolodimby, J., and Nacoulma, O. G. (2013). Antioxidant activity of phenolic and flavonoid fractions of Cleome gynandra and Maerua angolensis of Burkina Faso. J. Appl. Pharm. Sci. 3, 036-042. doi: 10.7324/JAPS.2013.30207

Moyo, M., Amoo, S. O., Ncube, B., Ndhalala, A. R., Finnie, J. F., and van Staden, J. (2013). Phytochemical and antioxidant properties of unconventional leafy vegetables consumed in southern Africa. S. Afr. J. Bot. 84, 65-71. doi: 10.1016/j.sajb.2012.09.010

Mueller-Harvey, I. (2001). Analysis of hydrolysable tannins. Anim. Feed Sci. Technol. 91, 3-20. doi: 10.1016/S0377-8401(01)00227-9

Narendhirakannan, R. T., Kandaswamy, M., and and Subramanian, S. (2005). Anti-inflammatory activity of Cleome gynandra L. leaves on hematological and cellular consitituents in adjuvant induced arthritic rats. J. Med. Food 8, 93-99. doi: $10.1089 / \mathrm{jmf} .2005 .8 .93$

Pandey, M., Verma, R. K., and Saraf, S. A. (2010). Nutraceuticals: new era of medicine and health. Asian J. Pharm. Clin. Res. 3, 11-15.

Prieto, P., Pineda, M., and Anguliar, M. (1999). Spectrophotometric quantitation of antioxidant capacity through the formation of phosphomolybdenum complex: specific application to the determination of vitamin E. Anal. Biochem. 269, 337-341. doi: 10.1006/abio,.1999.4019

R Core Team (2021). R: A Language and Environment for Statistical Computing. Vienna: R Foundation for Statistical Computing.

Rozita, N., Fatemeh, F., Pouya, H., Fazel, N. S., Solomon, H., Hosein, F. H., et al. (2018). Anthocyanins in the management of metabolic syndrome: a pharmacological and biopharmaceutical review. Front. Pharmacol. 9:1310. doi: 10.3389/fphar.2018.01310

Sarker, U., Hossain, M. N., Iqbal, M. A., and Oba, S. (2020a). Bioactive components and radical scavenging activity in selected advance lines of salt-tolerant vegetable Amaranth. Front. Nutr. 7:587257. doi: 10.3389/fnut.2020.587257

Sarker, U., Islam, T., and Oba, S. (2018a). Salinity stress accelerates nutrients, dietary fiber, minerals, phytochemicals and antioxidant activity in Amaranthus tricolor leaves. PLoS ONE 13:e0206388. doi: 10.1371/journal.pone. 0206388

Sarker, U., Islam, T., Rabbani, G., and Oba, S. (2015a): Genotype variability in composition of antioxidant vitamins and minerals in vegetable amaranth. Genetika 47, 85-96. doi: 10.2298/GENSR1501085S

Sarker, U., Islam, T., Rabbani, G., and Oba, S. (2015b). Variability, heritability and genetic association in vegetable amaranth (Amaranthus tricolor L.). Span. J. Agric. Res. 13:e0702. doi: 10.5424/sjar/2015132-6843

Sarker, U., Islam, T., Rabbani, G., and Oba, S. (2017). Phenotypic divergence in vegetable amaranth for total antioxidant capacity, antioxidant profile, dietary fiber, nutritional and agronomic traits. Acta Agriculturae Scandinavica B. Soil Plant Sci. 68, 67-76. doi: 10.1080/09064710.2017.1367029
Sarker, U., Islam, T., Rabbani, G., and Oba, S. (2018b). Variability in total antioxidant capacity, antioxidant leaf pigments and foliage yield of vegetable amaranth. J. Integr. Agric. 17, 1145-1153. doi: 10.1016/S2095-3119(17)61778-7

Sarker, U., Islam, T., Rabbani, G., and Oba, S. (2018c). Antioxidant leaf pigments and variability in vegetable amaranth. Genetika 50, 209-220. doi: 10.2298/GENSR1801209S

Sarker, U., and Oba, S. (2018a). Augmentation of leaf color parameters, pigments, vitamins, phenolic acids, flavonoids and antioxidant activity in selected Amaranthus tricolor under salinity stress. Sci. Rep. 8:12349. doi: 10.1038/s41598-018-30897-6

Sarker, U., and Oba, S. (2018b). Catalase, superoxide dismutase and ascorbateglutathione cycle enzymes confer drought tolerance of Amaranthus tricolor. Sci Rep 8:16496. doi: 10.1038/s41598-018-34944-0

Sarker, U., and Oba, S. (2018c). Drought stress effects on growth, ROS markers, compatible solutes, phenolics, flavonoids, and antioxidant activity in Amaranthus tricolor. Appl Biochem. Biotechnol. 186, 999-1016. doi: 10.1007/s12010-018-2784-5

Sarker, U., and Oba, S. (2018d). Drought stress enhances nutritional and bioactive compounds, phenolic acids and antioxidant capacity of Amaranthus leafy vegetable. BMC Plant Biol. 18:258. doi: 10.1186/s12870-018-1484-1

Sarker, U., and Oba, S. (2018e). Response of nutrients, minerals, antioxidant leaf pigments, vitamins, polyphenol, flavonoid and antioxidant activity in selected vegetable amaranth under four soil water content. Food Chem. 30, 72-83. doi: 10.1016/j.foodchem.2018.01.097

Sarker, U., and Oba, S. (2019a). Antioxidant constituents of three selected red and green color Amaranthus leafy vegetable. Sci. Rep. 9:18233. doi: 10.1038/s41598-019-52033-8

Sarker, U., and Oba, S. (2019b). Nutraceuticals, antioxidant pigments, and phytochemicals in the leaves of Amaranthus spinosus and Amaranthus viridis weedy species. Sci. Rep. 9:20413. doi: 10.1038/s41598-019-50977-5

Sarker, U., and Oba, S. (2019c). Protein, dietary fiber, minerals, antioxidant pigments and phytochemicals, and antioxidant activity in selected red morph Amaranthus leafy vegetable. PLoS ONE 14:e0222517. doi: 10.1371/journal.pone.0222517

Sarker, U., and Oba, S. (2019d). Salinity stress enhances color parameters, bioactive leaf pigments, vitamins, polyphenols, flavonoids and antioxidant activity in selected Amaranthus leafy vegetables. J. Sci. Food Agric. 99, 2275-2284. doi: $10.1002 /$ jsfa. 9423

Sarker, U., and Oba, S. (2020a). Leaf pigmentation, its profiles and radical scavenging activity in selected Amaranthus tricolor leafy vegetables. Sci. Rep. 10:18617. doi: 10.1038/s41598-020-66376-0

Sarker, U., and Oba, S. (2020b). Nutraceuticals, phytochemicals, and radical quenching ability of selected drought-tolerant advance lines of vegetable amaranth. BMC Plant Biol. 20:564. doi: 10.1186/s12870-020-02780-y

Sarker, U., and Oba, S. (2020c). Nutrients, minerals, pigments, phytochemicals, and radical scavenging activity in Amaranthus blitum leafy vegetables. Sci. Rep. 10:3868. doi: 10.1038/s41598-020-59848-w

Sarker, U., and Oba, S. (2020d). Nutritional and bioactive constituents and scavenging capacity of radicals in Amaranthus hypochondriacus. Sci. Rep. 10:19962. doi: 10.1038/s41598-020-71714-3

Sarker, U., and Oba, S. (2020e). Polyphenol and flavonoid profiles and radical scavenging activity in leafy vegetable Amaranthus gangeticus. BMC Plant Biol. 20:499. doi: 10.1186/s12870-020-02700-0

Sarker, U., and Oba, S. (2020f). The response of salinity stress-induced A. tricolor to growth, anatomy, physiology, non-enzymatic and enzymatic antioxidants. Front. Plant Sci. 11:559876. doi: 10.3389/fpls.2020.559876

Sarker, U., Oba, S., and Daramy, M. A. (2020b). Nutrients, minerals, antioxidant pigments and phytochemicals, and antioxidant capacity of the leaves of stem amaranth. Sci. Rep. 10:3892. doi: 10.1038/s41598-020-60252-7

Sevgi, K., Tepe, B., and Sarikurkcu, C. (2015). Antioxidant and DNA damage protection potential of selected phenolic acids. Food Chem. Toxicol. 77, 15-21. doi: 10.1016/j.fct.2014.12.006

Shilla, O., Dinssa, F. F., Omondi, E. O., Winkelmann, T., and Abukutsa-Onyango, M. O. (2019). Cleome gynandra L. origin, taxonomy and morphology: a review. Afr. J. Agric. Res. 14, 1568-1583. doi: 10.5897/AJAR2019.14064

Shrin, A. P. R., and Prakash, J. (2010). Chemical composition and antioxidant properties of ginger root (Zingiber officinale). Med. Plant Res. 4:2674-2679. doi: 10.5897/JMPR09.464 
Singletone, V. L., and Rossi, J. A. (1965). Colorimetry of total phenolics with phosphomolybdic-phosphotungstic acid reagents. Am. J. Enol Vitic 16: $144-158$.

Sogbohossou, E. D., Achigan-Dako, E. G., Maundu, P., Solberg, S., Deguenon, E. M., Mumm, R. H., et al. (2018). A roadmap for breeding orphan leafy vegetable species: a case study of Gynandropsis gynandra (Cleomaceae). Hortic. Res. 5, 1-15. doi: 10.1038/s41438-017-0001-2

Sogbohossou, E. O. D., Achigan-Dako, E. G., Mumm, R., and de Vos, R. C. H. (2020). Natural variation in specialized metabolites in the leafy vegetable spider plant (Gynandropsis gynandra L. (Briq.)) in Africa and Asia. Phytochemistry 178:112468. doi: 10.1016/j.phytochem.2020.1 12468

Sogbohossou, E. O. D., Kortekaas, D., Achigan-Dako, E. G., Maundu, P., Stoilova, T., Van Deynze, A., et al. (2019). Association between vitamin content, plant morphology and geographical origin in a worldwide collection of the orphan crop Gynandropsis gynandra (Cleomaceae). Planta 250, 933-947. doi: 10.1007/s00425-019-03142-1

Somers, B., Dinssa, F. F., Wu, Q., and Simon, J. E. (2020). Elemental micronutrients, antioxidant activity, total polyphenol, and total flavonoid content of selected spider plant accessions (Cleome gynandra) grown in Eastern Africa and the Eastern United States. J. Med. Act. Plants 9, 157-165. doi: 10.7275/jnrp-3y92

Sowinmi, L., and Afolayan, A. (2015). Phytochemical constituents and antioxidant properties of acetone extract of Cleome gynandra, L. growing in the eastern Cape, South Africa. J. Tradit. Complement. Altern. Med. 12, 1-8. doi: 10.4314/ajtcam.v12i3.1

Stangeland, T., Remberg, S. F., and Lye, K. A. (2009). Total antioxidant activity in 35 Ugandan fruits and vegetables. Food Chem. 113, 85-91. doi: 10.1016/j.foodchem.2008.07.026

Tonutare, T., Moor, U., and Szajdak, L. (2014). Strawberry anthocyanin determination by $\mathrm{pH}$ differential spectroscopic method- How to get true results? Acta Sci. Plo. Hortorum Cultus 13, 35-47.

Trilochana, Y., Babu, D. J. M., and Rao, P. R. (2017). The study of anti-diabetic activity of aqueous extract of Gynandropsis gynandra in diabetic rats. Indian J. Res. Pharm. Biotechnol. 5, 13-18. Available online at: http://www.ijrpb.com
Tuli, R. T., Rahman, M. M., Abdullah, A. T., Akhtauzzaman, M., and Islam, S. N. (2016). Phytochemicals- Tannins in some leafy vegetables of Bangladesh. Indian J. Nutri 3:150. Available online at: https://www.opensciencepublications.com/ fulltextarticles/IJN-2395-2326-3-150.html

Uusiku, N. P., Oelofse, A., Duodu, K. G., Bester, M. J., and Faber, M. (2010). Nutritional value of leafy vegetables of sub-Saharan Africa and their potential contribution to human health: a review. J. Food Composition Anal. 23, 499-509. doi: 10.1016/j.jfca.2010.05.002

van der Walt, A. M., Loots, D. T., Ibrahim, M. I. M., and Bezuidenhout, C. C. (2009). Minerals, trace elements and antioxidant phytochemicals in wild African dark-green leafy vegetables (morogo). S. Afr. J. Sci. 105, 444-448. http://www.scielo.org.za/scielo.php?script=sci_arttext\&pid=S003823532009000600016

Zhang, Y. J., Gan, R. Y., Li, S., Zhou, Y., Li, A. N., Xu, D. P., et al. (2015). Antioxidant phytochemicals for the prevention and treatment of chronic diseases. Molecules 20, 21138-21156. doi: 10.3390/molecules201219753

Conflict of Interest: The authors declare that the research was conducted in the absence of any commercial or financial relationships that could be construed as a potential conflict of interest.

Publisher's Note: All claims expressed in this article are solely those of the authors and do not necessarily represent those of their affiliated organizations, or those of the publisher, the editors and the reviewers. Any product that may be evaluated in this article, or claim that may be made by its manufacturer, is not guaranteed or endorsed by the publisher.

Copyright (C) 2021 Chataika, Akundabweni, Houdegbe, Achigan-Dako, Sibiya and Masamba. This is an open-access article distributed under the terms of the Creative Commons Attribution License (CC BY). The use, distribution or reproduction in other forums is permitted, provided the original author(s) and the copyright owner(s) are credited and that the original publication in this journal is cited, in accordance with accepted academic practice. No use, distribution or reproduction is permitted which does not comply with these terms. 